\title{
An approach to integrated teaching for the subject of malnutrition
}

\author{
Ganapathy Kalaiselvan ${ }^{1}$, Amol R Dongre ${ }^{2}$, Mahalakashmy. $T^{3}$
}

\section{Introduction}

The Medical Council of India recommends integration of subjects in the undergraduate curriculum for medical undergraduates and also at the regional level; The University of Pondicherry strongly recommends integration in medical curriculum. However, in most of the medical colleges, the subjects are taught in isolation with little or no attempt to integrate the basic sciences with the clinical discipline. To begin with when multi-disciplinary integration for selected topics was introduced in our recently initiated medical institution, it was observed that there was often a lack of students' involvement in the sessions. As a result, these students perceived integrated teachings as monotonous like other didactic lectures.

Malnutrition is an important child health problem in India. According to National Family Health Survey (2005-2006), 40\% of children under three are underweight. Students' exposure to this important child health problem was fragmented in different disciplines of undergraduate course. Hence, we decided to organize participatory skill based integrated teaching session on the topic of malnutrition within the existing teaching curriculum and assess its effect from students view point as it was a new approach to us.

\footnotetext{
1, 2, 3 Department of Community Medicine,

Sri Manakula Vinayagar Medicine College and Hospital, Pondicherry, India
}

Corresponding author:

Dr. G. Kalaiselvan, Associate Professor,

Department of Community Medicine

Sri Manakula Vinayagar Medical College and Hospital, Kalitheerthalkuppam, Madhagadipet,

Pondicherry- 605107, India

Email:kalaiselvanmd@gmail.com

\section{Methodology}

The present study was constructed after receiving permission from the Director of the Institute. A brief outline of topic of malnutrition was introduced to a batch of third year medical undergraduates through a multi-disciplinary integrated session of six hours durations (2 hours each day for 3 days). Out of 123 students 78 students $(63.4 \%)$ attended the entire 3 day program. The teaching faculties from the physiology, biochemistry, community medicine and pediatrics worked out a time table and guided and facilitated sessions on basics, causes, diagnosis and management of malnutrition. A demonstration cum hands on experience on anthropometric measurements such as weight, height, mid-arm circumference was undertaken. Students were taught to plot and interpret growth charts. Apart from this, the students made presentations on Integrated Child Development Scheme (ICDS) and Integrated Management of Neonatal and Childhood Illness (IMNCI), a recent government initiative under the Reproductive and Child Health $(\mathrm{RCH})$ program. Students recapped of learning of the previous day. Later, 78 students were divided into eight small self-managed groups and each group was asked to select a team leader and a volunteer to facilitate and to record the discussion. Each group was given a malnutrition case to discuss. The group work was presented and students were encouraged to interact actively. At the end, retro-pre feedback was taken from the students. The 'retro-pre design' was adopted to control the response 'shift bias' which was likely to take place due to students' limited knowledge about the topic. To avoid 'social desirability bias', the information such as name and sex was not collected. The data was entered in software package Statistical Package for Social Sciences (SPSS) version 11.5. Paired-t test was applied to find out the difference in the mean of the pre and post score values. Ethical principles such as obtaining informed written consent and ensuring confidentiality was followed. 


\section{Analysis and Discussion}

Overall this session was well received by the students with active participation. In the analysis of retro-pre feedback questionnaire, responses to all the questions were highly significant $(p<0.001)$. Students appreciated the process of participatory approach of integrated teaching and it also gave them the opportunity to learn the right method of measuring anthropometric measurements and plotting the growth chart which can be applied during their community posting $(p<0.001)$. In conventional didactic sessions, skills such as anthropometric measurements are given less importance. Students felt that the group work approach to interpret the plotted weight on the growth chart and identify the grade of malnutrition will be useful in their future clinical practice $(p<0.001)$. Overall, the participatory approach in integrated teaching for the topic of malnutrition was found to be better than regular integrated lectures based on only lectures $(p<0.001)$.
Thus, the integrated teaching session on a topic of public health importance with involvement of faculty from other para-clinical and clinical departments was well received by students. According to report of regional meeting on 'Teaching of public health in medical schools' in 2009, teaching of public health should be the combined responsibility of the Department of Community Medicine and other para-clinical and clinical departments.

\section{References}

Using the retrospective Post-then-Pre design. [Online], Available at: http://www.uwex.edu/ ces/pdande/resources/pdf/Tipsheet27.pdf [Accessed November 1, 2010].

Skeff, K.M., Georgetite, A., Stratos, G.A., Bergen, M.R. (1992) Evaluation of a medical faculty development program - A comparison of traditional pre/post and retrospective pre/post self-assessment. Eval Health Prof. Sep, 15, 3, pp. 350-366. 